\title{
Editorial
}

\section{Nursing (on) a Sick Planet: Critical Consciousness and Action in a Time of Planetary Decline}

\author{
Wanda Martin ${ }^{1}$ RN, BScN, MN, Ph.D. \& June Kaminski² RN, BSN, MSN, Ph.D. (c) \\ ${ }^{1}$ Associate Professor, College of Nursing, University of Saskatchewan; ${ }^{2}$ Nursing Curriculum Coordinator, \\ Research Coordinator, Informatics \& E-Learning, Kwantlen Polytechnic University.
}

Cite As: Martin, W. \& Kaminski, J. (2021). Nursing (on) a sick planet: Critical consciousness and action in a time of planetary decline. Witness: The Canadian Journal of Critical Nursing Discourse, Vol 3(2), pp 1-5. https://doi.org/10.25071/2291-5796.119

Nurses in Canada and worldwide have been experiencing a healthcare system under the strain of the Covid-19 pandemic. With the effects of climate change, what is to come will likely be even more straining, particularly if healthcare providers and administrators are not prepared. This special issue invited nurses to dive into the complexities of climate change and the ecological determinants of health and consider essential concepts related to nursing. The nursing profession is experiencing a change in thinking toward an expanded environmental context, as nurses witness the ever-increasing destructive land use, pollution, and greenhouse gas emissions that ignore gross inequities in environmental burdens that bring us closer to catastrophic consequences (Kurth, 2017). The papers in this special issue provide some direction for nurses to help prepare themselves and the system for what lies ahead. We want to add some additional considerations relating to nursing (on) a sick planet in a time of planetary decline.

As we see it, there are two main areas for nurses to consider in preparing the healthcare system for an unpredictable future and prevention work to support future generations. The first is for nurses and the wider population to understand that climate and environmental sustainability are nurses' work. As such, nurses need to understand adaptation and mitigation as the planet experiences changes due to greenhouse gas emissions. The second is for nurses, as health leaders, to come together with a powerful voice and contribute to the other voices calling for a shift in how we operate as a society.

National and international nursing organizations support this voice. They have created position statements that guide nurses to become advocates for climate change mitigation and adaptation processes, especially in the context of vulnerable populations (International Council of Nurses, 2018; Canadian Nurses Association, 2017).

Nursing is often viewed in a narrow context of caring for the ill, disabled, and dying. Working in health promotion and prevention of illness at a population health level is a dwindling opportunity for Canadian nurses (Domm \& Urban, 2020). Population health is not often seen as a priority for baccalaureate programs where nurses need to be educated for the positions they will most likely take up in the acute care system. Not many nurses are in positions where the primary focus of the work is to support a healthy environment, although it is within nursing's domain of practice. Of course, understanding the social determinants of health is very relevant for all nurses, but much less focus is placed on the 
The Canadian Journal of Critical Nursing Discourse

See it. Speak it. Write it. Change it.

environmental determinants of health. The environmental factors make up the context for the social determinants and are at the root of what makes a population healthy.

Populations most vulnerable to climate change and planetary health issues often suffer from risks to their social and environmental determinants of health. Extreme weather events linked to advancing climate change impact vulnerable populations disproportionately and in fundamental ways, affecting people's ability to access basic food security, mobility, housing, and health/social services. In 2021 alone, various regions of Canada endured heat-dome and wildfire effects during the summer months and extreme flooding and landslides during the fall. These changes have put several communities at risk, including Indigenous rural and remote communities.

The concept of 'environment' in the nursing metaparadigm is not new and has been expanding for decades (see Stevens, 1989; Institute of Medicine (US) Committee on Enhancing Environmental Health Content in Nursing et al., 1995; Kleffel et al., 2006; Potter, 2019). It is now clear that the very foundation for a healthy life - the air we breathe and water and food that sustain us is part of the environment in the nursing metaparadigm. At one time, the local, immediate space constituted the environment in the domain of nursing care (Thorne et al., 1998; Kalogirou et al., 2020). Now nursing is working farther upstream, developing a critical consciousness, linking the biophysical environment to social justice and health equity (Kalogirou et al., 2020). Opening a window for fresh air was a good start, but now the work extends to advocating for a high standard of air quality and understanding the links between asthma, pollen, and allergies, for example. Many nurses, however, do not embrace the environment in such a way as to have the nursing profession recognized as leaders in climate and environmental sustainability. Even if more nurses were working at the population health level, how many would be in a position to take environmental sustainability as central to their practice? At the most, we can ask that nurses weave sustainability concepts into their daily work. And we are asking this at a time when many nurses have not been educated in sustainability practice and when the health care system is experiencing considerable strain.

Since climate change profoundly impacts human and planetary health, nurses must adopt a collective stance that promotes advocacy and education across all spectrums of nursing practice, research, and education to support climate change resilience. Nurses can be instrumental in promoting practices, policies, and programs that support this resilience in all populations (Canadian Nurses Association, 2017).

Canadian nursing curriculum is beginning to incorporate climate change and health concepts. The new generation of nurses are beginning to imagine their practice in 20 years and question their role in preventing the ill effects of climate scientists' predictions. The educators' responsibility is to prepare nurses, not on what they have experienced, but for what nurses will see in the future. The public will look to nurses, as trusted health care professionals, for knowledge and support as we all experience environmental burdens. Educators need to ask how well prepared the new nurses will be in a changing reality and recognize that the environmental context has a significant impact on the health of a population. Once nursing has accepted the expanded view of the environment and the professional responsibility of supporting the population in a climate crisis, the real work of adapting to how we do business and mitigating greenhouse gas emissions can begin. We need to think about the drive for curriculum integration of planetary health concepts critically. In particular, what do nurses need to learn that they are not already learning in basic $\mathrm{BScN}$ programs?

The call for culturally competent, safe, and humble healthcare is an emerging mandate of 
most Canadian nursing education programs, with a strong directive to support Indigenous clients and communities. An integral part of this mandate is to support Indigenous knowledge and ties to the land. The land is seriously impacted by climate change and resultant weather changes and disasters. Nursing students need to know how to assess and support individual, family, and community adaptation to these changes as part of current and future care. Nurses must learn to protect the rights of vulnerable groups that are less climate-resilient and more at risk for the adverse health effects of climate change.

Environmental literacy or eco-literacy is emerging as a critical component of education for Canadians and is beginning to be included at all levels of education, including nursing education. Traditional Indigenous teachings and philosophies are the most logical source of sustainability knowledge that promotes ecological wholeness. Nursing educational programs are beginning to incorporate Indigenous principles related to the land into the curriculum to help evolve eco-literacy and advocacy skills/knowledge. Ecologically literate students can be nurtured to participate as community builders and activists to find solutions to climate change impacts on health. Social justice initiatives that focus on giving voice to the most vulnerable and supporting climate resilience policies and practices are emerging.

Beyond registered nurses' daily work, there is a powerful collective voice and an opportunity to enhance population health. Duhaime and colleagues (2021) advocate that healthcare professionals adopt a climate collaborators' mindset, working across sectors and learning from experts in other fields. While nurses may not solve the climate crisis, they can work to influence their immediate domain of the healthcare system. Healthcare professionals can identify changes to green the healthcare system by working with engineering, architecture, environmental science, agriculture, economics, and policy (Duhaime et al., 2021). We have that work started in Canada, but every nurse needs to be pushing in the same direction to shift toward a healthier future. What will it take to harness the power of nursing?

Nurses can be active supporters of their own eco-literacy and the eco-literacy of others. When nurses speak up about climate change and its effects on health in a collective way, they can provide a powerful impetus for change and climate justice. Providing culturally appropriate advocacy support to emerging initiatives by various populations such as Indigenous communities can be an essential part of this work that acknowledges rights-based changes and actions needed to reduce the impacts of climate change. Nurses can support "...culturally appropriate ways to understand, mitigate and adapt to these health impacts and enhance our wellness and resilience in the face of our new climate and environmental reality" (Inuit Tapiriit Kanatami, 2019, p. 22). A fundamental principle that serves as a baseline for all action is that human and planetary health are intrinsically linked.

Serhan (2021) describes the 3.5\% rule from the work of political scientist Chenoweth as an inspiration for Extinction Rebellion - a grassroots global organization formed to persuade governments to act justly on the climate and ecologic emergency (https://rebellion.global/about-us/). According to Chenoweth, serious political change is most likely to occur with $3.5 \%$ of the population actively engaged in non-violent protests (Serhan, 2021). Nurses can be part of that $3.5 \%$. There are numerous organizations engaged in climate action (350.org, Climate Action Network Canada, Canadian Association of Physicians for the Environment, and Canadian Association of Nurses for the Environment, to name a few).

There is a large body of nurses in Canada (roughly 440,000) and even more medical and allied health professionals. Collaborating with other organizations and making the environment a priority is a contribution that nursing can 
make. Shifting organizational norms, taking the leadership role, engaging in non-violent protests - nurses can meet the climate emergency in full force. We call on nurses to exhibit critical consciousness and action by engaging with

\section{References}

Canadian Nurses Association. (2017). Climate change and health. Position statement. https://www.cna-aiic.ca/en/policyadvocacy/policy-support-tools/positionstatements

Domm, E. \& Urban, A. M. (2020). Public health nurse perceptions of evolving work and how work is managed: A qualitative study. Journal of Nursing Management, 28(8), 2017-2024.

https://doi.org/https://doi.org/10.1111/jo nm. 13058

Duhaime, A.-C., Futernick, M., Alexander, M., Erny, B. C., Etzel, R. A., Gordon, I. O., Guinto, R., Hertelendy, A. J., Howard, C., Maki, L., Olagunju, A. T., Parker, E. R., Redvers, N., Sehgal, A., Shultz, J. M., Simidchiev, A., Torday, J. S., \& Zhang, Y. (2021). Healthcare professionals need to be CCLEAR: Climate collaborators, leaders, educators, advocates, and researchers. The Journal of Climate Change and Health, 4, 100078. https://doi.org/https://doi.org/10.1016/j.j oclim.2021.100078

International Council of Nurses (ICN). (2018). Nurses, climate change and health. Position statement. Available: https://www.icn.ch/news/internationalcouncil-nurses-calls-increased-nursingleadership-combat-effects-climatechange

Inuit Tapiriit Kanatami. (2019). National Inuit climate change strategy. https://www.itk.ca/wp- climate change organizations, demonstrating a commitment to social justice, and working towards a healthier future.

content/uploads/2019/06/ITK_ClimateChange-Strategy_English_lowres.pdf

Kalogirou, M.R., Olson, J., Davidson, S. (2020). Nursing's metaparadigm, climate change and planetary health. Nursing Inquiry, 27(3), e12356. https://doi.org/10.1111/nin.12356

Kleffel, D., Andrist, L. C., Nicholas, P. K., et al. (2006). The evolution of the environmental metaparadigm of nursing. A history of nursing ideas (pp. 97-108). Jones and Barlett.

Kurth, A. E. (2017). Planetary health and the role of nursing: a call to action. Journal of Nursing Scholarship, 49(6), 598-605.

Institute of Medicine (US) Committee on Enhancing Environmental Health Content in Nursing, Pope, A. M., Snyder, M. A., \& Mood, L. H. (Eds.). (1995). Nursing, health \& the environment: Strengthening the relationship to improve the public's health. National Academy Press (US).

Potter, T. (2019). Planetary health: The next frontier in nursing education. Creative Nursing, 25(3), 201-207. https://doi.org/10.1891/1078$\underline{4535.25 .3 .201}$

Stevens, P. (1989). A critical social reconceptualization of environment in nursing. Advances in Nursing Science, 11(4), 56-68.

Serhan, Y. (November 8, 2021). Can 3.5 percent save the planet? The Atlantic. Retrieved from

https://www.theatlantic.com/internationa 1/archive/2021/11/cop26-climateactivism/620641/ 
Thorne, S., Canam, C., Dahinten, S., Hall, W., Henderson, A., \& Kirkham, S. (1998).

Nursing's metaparadigm concepts:

Disimpacting the debates. Journal of

Advanced Nursing, 27(6), 1257-1268.

https://doi.org/10.1046/j.1365-

2648.1998.00623.x

The authors identify no conflict of

interest, necessity for ethical clearance

nor funding associated with this

editorial. 